\title{
Effects of preparation temperature on the conductivity of polypyrrole conducting polymer
}

\author{
ANUAR KASSIM*, ZARINA BTE BASAR and \\ H N M EKRAMUL MAHMUD \\ Department of Chemistry, Faculty of Science and Environmental Studies, \\ Universiti Putra Malaysia, 43400 Serdang, Selangor, Malaysia \\ e-mail: anuar@fsas.upm.edu.my
}

MS received 4 December 2001; revised 2 April 2002

\begin{abstract}
An attempt has been made to investigate the effect of temperature on the conductivity of polypyrrole conducting polymer films prepared by an electrochemical method in an aqueous medium using camphor sulfonate as the dopant. The polymer was grown from aqueous solutions employing a range of temperatures $\left(1-60^{\circ} \mathrm{C}\right)$. It was found that with increase in temperature the conductivity decreased and the optimum temperature was found to be between 10 and $30^{\circ} \mathrm{C}$. The results show that the polymer formed at low temperature has higher conductivity and is stronger than that formed at higher temperatures. Characterization by X-ray scattering shows that interlayer distance, $d_{\text {Bragg }}(\AA)$, increases with increasing temperature. The morphology of the films formed was studied by using a scanning electron microscope (SEM). The changes in conductivity and physical appearance were interpreted as being due to compactness in the molecular packing and formation of $\alpha \beta$ linkages in the film.
\end{abstract}

Keywords. Conducting polymer; polypyrrole; camphor sulfonate dopant; electrochemical polymerization.

\section{Introduction}

Interest in the development of conducting polymers such as polyaniline, polypyrrole, polythiophene, polyphenylene etc. has increased tremendously during the last decade because of their electronic properties for use in batteries, electronic devices, functional electrodes, electrochromic devices, optical switching devices, sensors and so on ${ }^{1-5}$. Conducting polymers can be prepared by chemical or electrochemical polymerization. In the chemical polymerization process, monomers are oxidized by oxidizing agents or catalysts to produce conducting polymers ${ }^{6,7}$. The advantage of chemical synthesis is that it offers mass production at reasonable cost. On the other hand, the electrochemical method involves the direct formation of conducting polymers with better control of polymer film thickness and morphology, which makes them suitable for use in electronic devices.

Polypyrrole is by far the most extensively studied conducting polymer since monomer pyrrole is easily oxidized, water-soluble, commercially available, and possesses environmental stability, good redox properties and high electrical conductivity ${ }^{8}$. Due to its good intrinsic properties, polypyrrole appears promising for use in batteries, super

*For correspondence 
capacitors, electrochemical (bio) sensors, conductive textiles and fabrics, mechanical actuators, electromagnetic interference shielding, anti-static coating and drug delivery systems $^{2}$.

Since the properties of the resultant films depend on a number of parameters, such as the type of counter-ion and solvent and their concentrations, and on other synthesis conditions, research on the preparation and characterization of conducting polymers is still continuing. Studies have been conducted on the effect of preparation temperature on conducting polymers using different dopants and solvents ${ }^{9-12}$ by electrochemical methods not thoroughly studied so far.

The present paper focusses on the effects of preparation temperature on the conductivity of polypyrrole films doped with camphor sulfonate dopant in aqueous medium. The probable causes for conductivity changes with change in temperature are sought through SEM and X-ray studies of the films.

\section{Experimental}

The polypyrrole (ppp-) films used in the present study were electrochemically prepared by the oxidation of pyrrole (Fluka) monomer with camphor sulfonate dopant (Fluka). The commercially available pyrrole monomer was distilled prior to use. Electrochemical synthesis was carried out in a one-compartment cell using a potentiostat under computer control. An indium-tin-oxide (ITO) glass was used as the working electrode (anode) while a carbon rod was used as the counter electrode (cathode). The anodic potential of the working electrode was measured as 1.2 volt against a saturated calomel electrode (SCE). The aqueous solution containing pyrrole of $0.2 \mathrm{M}$ concentration and dopant of $0 \cdot 1 \mathrm{M}$ concentration, was polymerized by the electrochemical method at $18^{\circ} \mathrm{C}$ for $5 \mathrm{~h}$ to form polypyrrole films of $0.1 \mathrm{~mm}$ thickness. Polypyrrole formed on the ITO glass surface as insoluble film was rinsed with distilled water and then peeled off from the electrode.

\subsection{Polymer characterization}

The polypyrrole films produced were characterized by scanning electron microscopy (JEOL JSM-6400 microscope), X-ray (Shimadzu X-ray diffractometer X-RD 6000), FTIR spectroscopy (Perkin-Elmer FTIR spectrophotometer), and conductivity measurement, by the four-probe technique at $25^{\circ} \mathrm{C}$.

\section{Results and discussion}

Pyrrole monomer doped with camphor sulfonate in aqueous phase produced uniform polypyrrole films of about $0.10 \mathrm{~mm}$ thickness. Conductivities of the resulting polypyrrole films are given in table 1 . We see that with increase in preparation temperature, the conductivity decreases (figure 1).

\subsection{SEM analysis}

Scanning Electron Microscopy was used to study the morphology of the films at various magnifications. It was observed that the degree of smoothness of the films decreases as the preparation temperature increases (table 1). It is believed that the roughness of the films is related to the change in chain bonding through $\alpha \alpha$ to $\beta-\beta$. The $\alpha \alpha$ chain 
bonding results in a very smooth surface of the film but as the $\beta$ - $\beta$ bonding dominates, the surface becomes rough. Increasing the temperature causes increase in interactions between monomer and polymer, and monomer and monomer. Hence, this increases the chances of polymerization through $\alpha-\beta$ and $\beta-\beta$ rather than $\alpha \alpha$ chain bonding. This is why the physical appearance of the polypyrrole films gradually changes from smooth to rough with the increase of preparation temperature. Closer observation using Scanning Electron Microscopy (SEM) confirms our findings that surface morphology at low temperature is smoother than at high temperature (figure 2). It clearly shows that at low

Table 1. Conductivity and physical properties of the polypyrrole films at $25^{\circ} \mathrm{C}$.

\begin{tabular}{|c|c|c|}
\hline Temperature $\left({ }^{\circ} \mathrm{C}\right)$ & Conductivity $(\mathrm{S} / \mathrm{cm})$ & Physical properties \\
\hline $1 \cdot 2$ & $26 \cdot 26$ & $\begin{array}{l}\text { Smooth } \\
\text { Coherent }\end{array}$ \\
\hline $9 \cdot 8$ & $16 \cdot 65$ & $\begin{array}{l}\text { Smooth } \\
\text { Wrinkled }\end{array}$ \\
\hline $16 \cdot 8$ & $12 \cdot 96$ & $\begin{array}{l}\text { Smooth } \\
\text { Wrinkled }\end{array}$ \\
\hline $35 \cdot 4$ & $2 \cdot 81$ & $\begin{array}{l}\text { Rough } \\
\text { Wrinkled }\end{array}$ \\
\hline $45 \cdot 9$ & $0 \cdot 22$ & $\begin{array}{l}\text { Rough } \\
\text { Wrinkled }\end{array}$ \\
\hline $59 \cdot 8$ & $0 \cdot 04$ & $\begin{array}{l}\text { Rough } \\
\text { Wrinkled }\end{array}$ \\
\hline
\end{tabular}

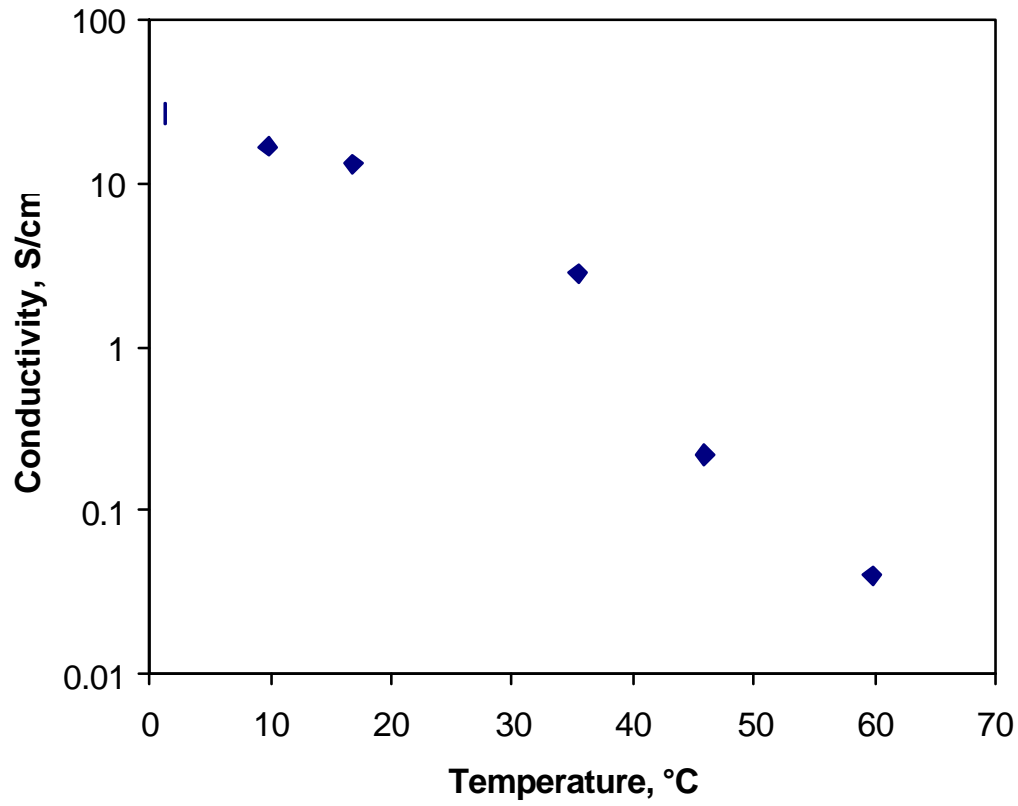

Figure 1. The effect of temperature on conductivity. 
(a)

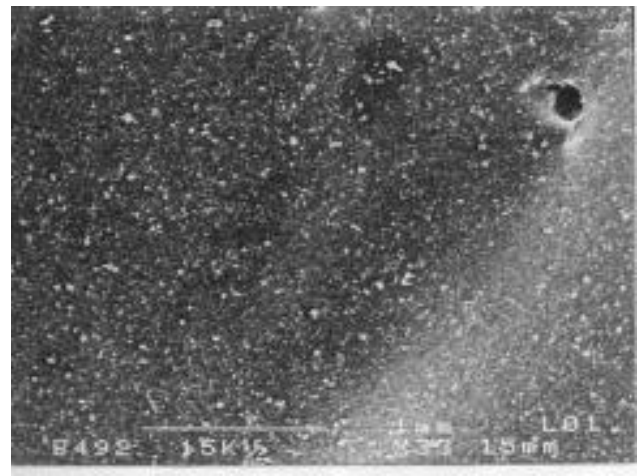

(b)

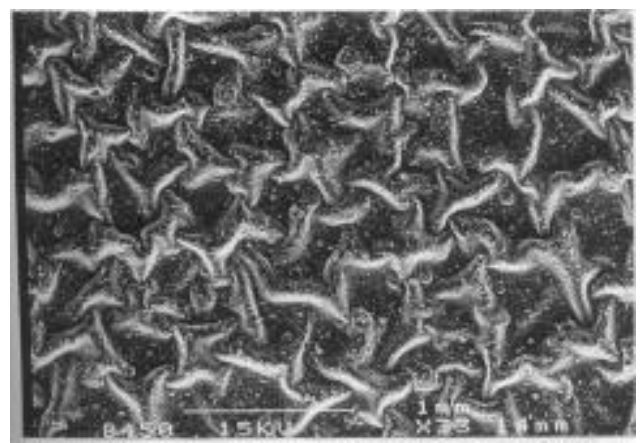

(c)

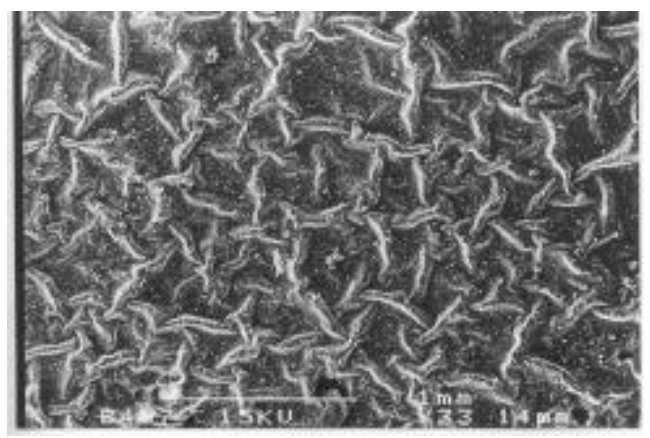

Figure 2. SEM micrographs (magnification 33 times) of the films prepared at (a) $1 \cdot 2^{\circ} \mathrm{C}$, (b) $35 \cdot 4^{\circ} \mathrm{C}$ and (c) $45 \cdot 9^{\circ} \mathrm{C}$.

temperature, namely $1.2^{\circ} \mathrm{C}$, the surface is smooth and no wrinkle is seen (figure $2 \mathrm{a}$ ). The smooth surface texture changes to a more undulating wrinkled appearance at higher temperatures. This is seen by examining the film prepared at $45.9^{\circ} \mathrm{C}$, which tends to form many wrinkles and fractures (figure $2 \mathrm{c}$ ).

Micrographs at 2500 magnification (figure 3) show the growth of the film formed by overlapping globular or nodule morphology. The distribution of nodule sizes also increases which leads to surface roughness as the preparation temperature increases. It can be observed from figure 3 that the film is made up of many globular structures joined to one another. There is also side growth observed from the surface of the film that form bordered nodules. 


\section{$3.2 X$-ray analysis}

Analysis of the $X$-ray curves shows two peaks at $2 \theta=25^{\circ}$ and $17^{\circ}$ respectively (figure 4 ). These peaks were previously observed by Kassim et al ${ }^{13}$ using the same dopant at room temperature. The peak at $25^{\circ}$ is assigned to the interlayer distance, $d_{\mathrm{Bragg}}$, from the pyrrole to the pyrrole ring in the polymer and that at $17^{\circ}$ is the interlayer distance, $d_{\mathrm{Bragg}}$, from the pyrrole ring to the camphor sulfonate dopant.

(a)

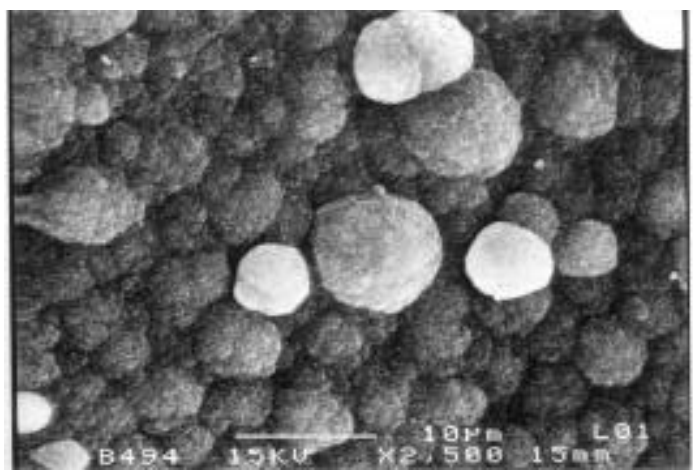

(b)

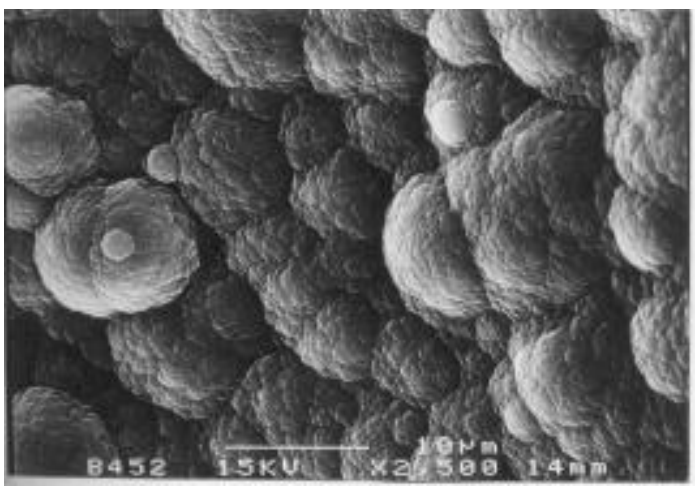

(c)

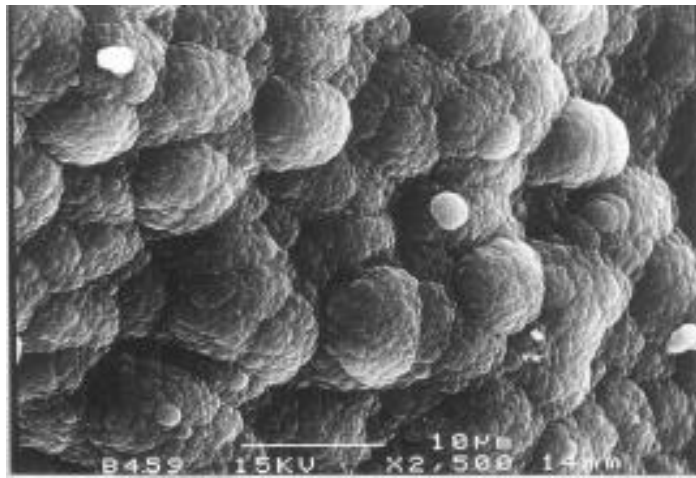

Figure 3. SEM micrographs (magnification 2500 times) of the films prepared at (a) $1 \cdot 2^{\circ} \mathrm{C}$, (b) $35 \cdot 4^{\circ} \mathrm{C}$ and (c) $45 \cdot 9^{\circ} \mathrm{C}$. 


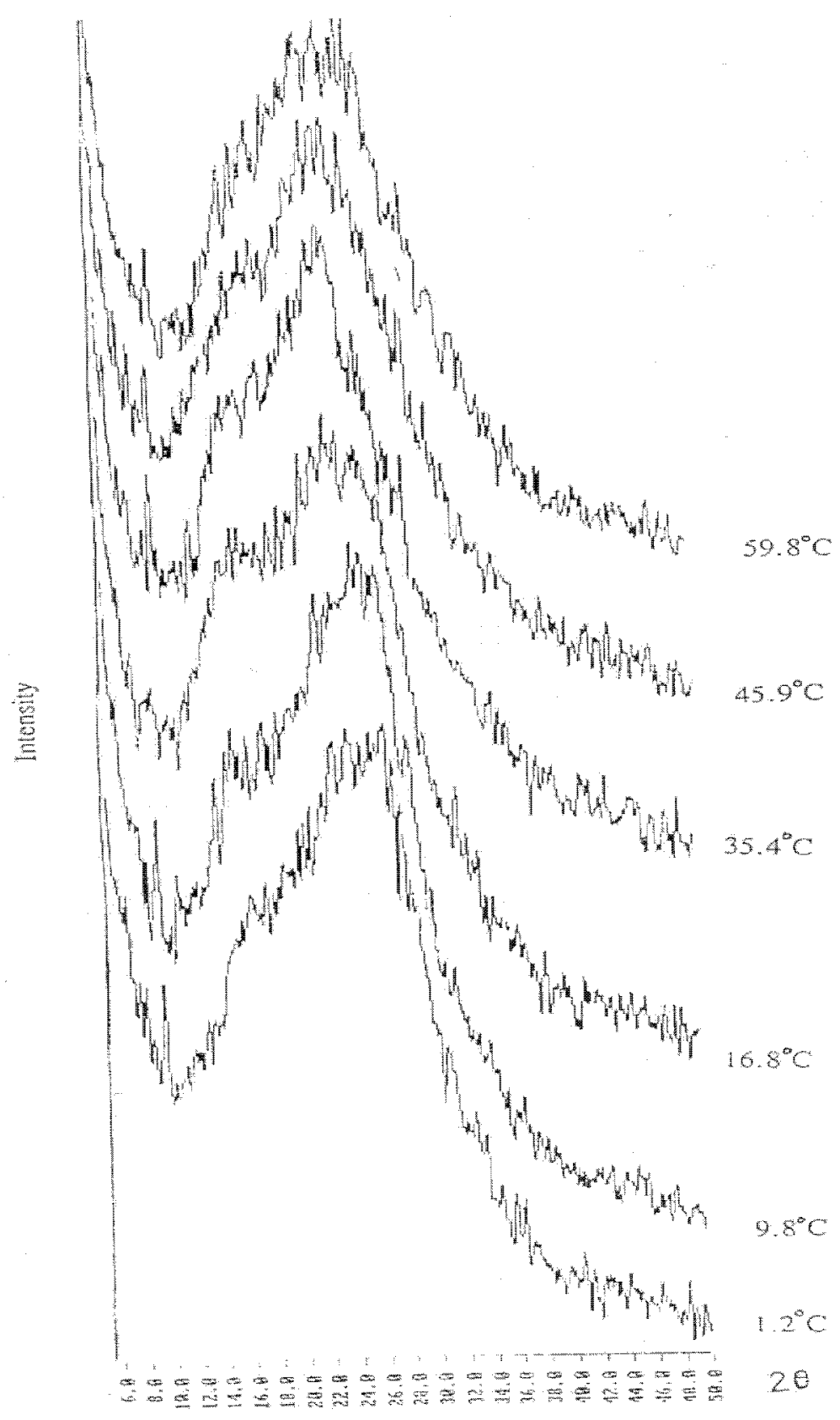

Figure 4. The X-ray diffraction for the films prepared at various temperatures.

A closer analysis of the X-ray diffraction pattern shows some variations. Due to increase in preparation temperature, the $2 \theta$ values shift from $25 \cdot 50^{\circ}$ to $22.55^{\circ}$ with the $d$ spacing varying from $3.49 \AA$ to $3.94 \AA$ respectively. Table 2 shows the data obtained from X-ray diffraction. The $d$-spacing or interlayer distance is calculated from Bragg's 
equation. It is observed that the $d$-spacing increases as preparation temperature increases and reaches a maximum value. The larger the $d$-spacing between the pyrrole rings, the more difficult it is for the electrons to hop from one layer to the next layer and hence this reduces the value of its conductivity. Further analysis at the same $2 \boldsymbol{\theta}$ shows that the $L_{h k l} / d$-spacing ratio (short range order), which shows the presence of polymer layer per unit distance, which is equivalent to compactness of the film, is greater at low temperature than at high temperature. This $L_{h k l} l d$-spacing ratio strongly supports the view that not only shorter $d$-spacing but also the compactness of the film would help to enhance the conductivity of the film formed. The more compact the film, the stronger the film is, and vice versa.

Table 2. Values of $2 \theta$ angle with various temperatures.

\begin{tabular}{|c|c|c|c|c|c|}
\hline Temperature $\left({ }^{\circ} \mathrm{C}\right)$ & $2 \theta$ angle (degrees) & $d$ spacing $(\AA)$ & $\beta_{1 / 2}$ & $L_{h k l}$ & $L_{h k l / d \text { spacing }}$ \\
\hline $1 \cdot 2$ & $25 \cdot 50$ & $3 \cdot 49$ & $7 \cdot 1$ & $25 \cdot 51$ & $7 \cdot 31$ \\
\hline $9 \cdot 8$ & $25 \cdot 00$ & $3 \cdot 56$ & $7 \cdot 1$ & $25 \cdot 49$ & $7 \cdot 16$ \\
\hline $16 \cdot 8$ & $23 \cdot 53$ & 3.78 & 8.9 & $20 \cdot 22$ & $5 \cdot 35$ \\
\hline $35 \cdot 4$ & $22 \cdot 55$ & 3.94 & 8.9 & $20 \cdot 22$ & $5 \cdot 13$ \\
\hline $45 \cdot 9$ & $22 \cdot 55$ & 3.94 & $9 \cdot 8$ & $18 \cdot 44$ & 4.68 \\
\hline $59 \cdot 8$ & $22 \cdot 55$ & 3.94 & $10 \cdot 7$ & $16 \cdot 89$ & $4 \cdot 29$ \\
\hline
\end{tabular}

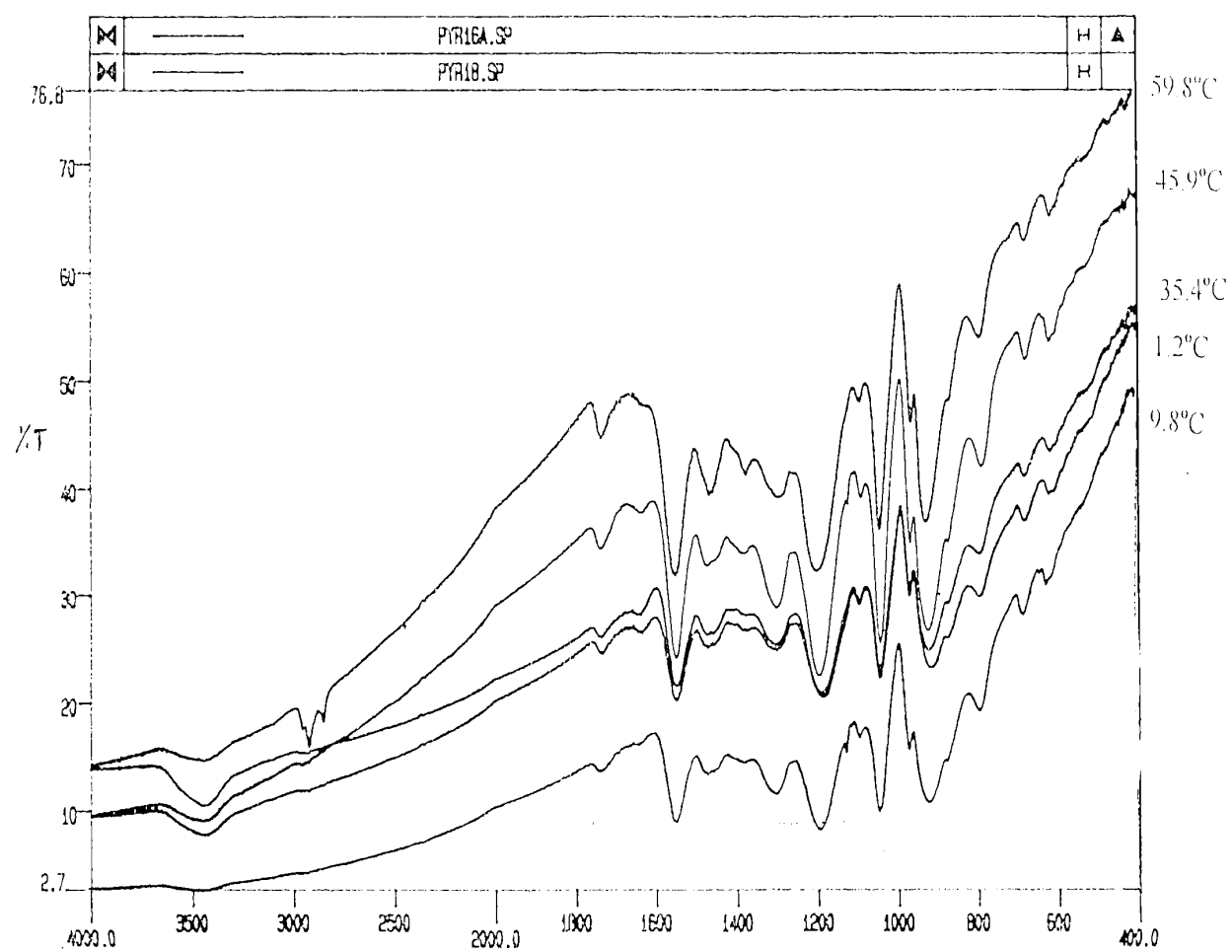

Figure 5. The FTIR spectra of all the films prepared at various temperatures. 


\subsection{Infrared spectra}

All samples show a medium absorption band at about 1732 to $1740 \mathrm{~cm}^{-1}$ which is due to $\mathrm{C}=\mathrm{O}$ stretching in the camphor sulfonate. $\mathrm{N}-\mathrm{H}$ bending occurs at $1540-1570 \mathrm{~cm}^{-1}$ in all samples examined. During cross-linking, some of the dopants may as well be trapped and form part of the polymer. The infrared spectrum (figure 5) shows that at higher preparation temperature, the peak at about wave number $2920-2960 \mathrm{~cm}^{-1}$, is due to the $\mathrm{C}-\mathrm{H}$ vibration in the $-\mathrm{CH}_{3}$ group. This peak can be clearly observed in this sample which is absent at in the one made at low temperature. This peak can only be explained by the presence of trapped dopant or the dislocation of dopant between polymer chain layers.

\section{Conclusions}

The conductivity of polypyrrole-camphorsulfonate films decreases as the preparation temperature increases. The optimum preparation temperature is about $10^{\circ}$ to $30^{\circ} \mathrm{C}$. Roughness factor, compactness and $d$-spacing distance are the main causes of the decreasing conductivity. Films formed at low preparation temperature are smooth, coherent and mechanically strong compared to those prepared at high temperature. X-ray analysis shows that at low preparation temperature, the polypyrrole film is more compact resulting in higher conductivity while at high preparation temperature, the film is less compact resulting in lower conductivity.

\section{Acknowledgement}

Financial support (IRPA-fund No. 09-02-04-0109) from the Ministry of Science \& Technology, Government of Malaysia, is gratefully acknowledged.

\section{References}

1. Tourillon G 1986 Handbook of conducting polymers (ed.) T A Skotheim (New York: Marcel Dekker) vol. 1, pp 293

2. Scrosati B 1993 Science and applications of conducting polymers (London: Chapman and Hall) ch. 7

3. Jasne S 1988 Encyclopedia of polymer science and engineering (New York: John Wiley) pp 51

4. Om Bockris J and Miller D 1989 Conducting polymers: Special applications (ed.) L Alcacer (Dordrecht: Reidel) pp 1

5. Palmisano F, De Benedetto G E and Zambonin C G 1997 Analyst 122365

6. Anuar K, Abdullah A H and Idris Z 2001 Ultrascience 122

7. Chao T H and March J 1988 J. Polym. Sci. A26 743

8. Ellis J R 1986 Handbook of conducting polymers (ed.) T A Skotheim (New York: Marcel Dekker) 1501

9. Ogasawara M, Funahashi K and Iwata K 1985 Mol. Cryst. Liq. Cryst. 118159

10. Satoh M, Kaneto K and Yoshino K 1986 Synth. Met. 14

11. Mitchell G R and Geri A 1987 J. Phys. D20 1346

12. Takakubo M 1986 Synth. Met. 16167

13. Kassim A, Davis F J and Mitchell G R 1994 Synth. Met. 6241 